Original Research Paper

\title{
Factors Influencing Online Shopping in Mauritius: An Application of Principal Component Analysis and Binary Logistic Regression
}

\author{
Ramtohul, P., N. Mamode Khan and M. Hosenally \\ University of Mauritius, Mauritius
}

Article history

Received: 17-09-2014

Revised: 19-09-2014

Accepted: 31-12-2014

Corresponding Author: N. Mamode Khan,

University of Mauritius,

Mauritius

Email: n.mamodekhan@uom.ac.mu

\begin{abstract}
In our modern world, the intensive use of internet has imposed new lifestyles and encouraged new behaviour amongst many across the globe. With the development in Internet technologies, the emergence of online shopping has altered the way businesses operate. While many of them have embraced this platform to present their offerings, many customers on the other hand, are finding it more cost-effective and convenient to carry out their transactions online. Therefore, the present study was undertaken to refine our understanding on consumers' attitudes, perception and behaviour towards online shopping in a Mauritian context. Data was collected among 224 respondents in Mauritius whereby a questionnaire was administered through personal interviews with the aim of achieving a higher response rate. Principle Component Analysis (PCA) was performed to reveal the underlying factors influencing people's perceptions and attitudes towards online shopping and the results uncovered that 'online shopping conveniences', 'security and product risk', 'complexity and waiting time' and 'enjoyment and pleasure' were major contributors to overall attitudes towards online shopping attributes. The binary regression model was also fitted and factors such as marital status and internet at home were the significant factors to contribute towards online shopping.
\end{abstract}

Keyword: Principal Component Analysis, Binary Logistic, Online Shopping, Security

\section{Introduction}

The Internet is a medium which is gaining popularity across the world. In an era of globalisation, the Internet has gone beyond networking and is now focusing on the delivering and trading of information, goods and services (Delafrooz et al., 2009). Advances in Internet technology are allowing business transactions to take place and have resulted in an expansion of shopping choices, beyond traditional methods which may impose time and displacement constraints. Nowadays, people across the globe have moved towards intensive use of Internet as a market channel, due to the number of advantages it offers. For instance, traditional shopping inconveniences are eliminated which makes online shopping even more appealing. Therefore, from banking, bill payment to purchasing, the Internet has brought forward a new platform for these activities to be undertaken. From a business perspective, the Internet is significantly altering the way retailers present their offerings, advertise, sell and communicate with customers. However, the tremendous growth of online shopping is not only driven by the wide range of benefits it provides to customers, but also by the improvement in security systems which is more and more dispelling the idea that online shopping is a risky business (Kim and Kim, 2004). Although Mauritius is experiencing a gradual proliferation of online shopping, relatively little is currently known about Mauritian online shopping in particular. Traditional shopping methods still persist and the integration of online shopping in Mauritians' lifestyle is at a pace far from those of similar developed nations where online shopping is already a common practice. However, it is undeniable that growth of internet use has encouraged new behaviour and new attitudes which should be explored to get a better understanding. Consumers' attitude relates to their psychological frame of mind towards online shopping (Guo et al., 2011) and is shaped by motivation and perception, which in turn 
influences their online purchase decisions (Delafrooz et $a l ., 2009)$. Therefore, taking into consideration that online shopping is still in its early stage of development, the purpose of this study is to fill that knowledge gap by exploring Mauritian attitudes and behaviour towards online shopping, in other words how they relate to this new shopping channel. The aim of the study is to analyze and understand attitudes, perception and behaviour of Mauritian residents towards online shopping.

The objectives of the study are to identify the different factors influencing online shopping behaviour among Mauritian people and to enquire how online shopping behaviour is related to demographics such as age, gender, income, occupation, education, marital status, internet access at home and predict future online shopping intentions based on these factors. The organization of the paper is as follows: In the next section, an overview on e-commerce is presented. In section 3 , we provide the methodology used to identify the factors based on the Principal Component Analysis (PCA). In the last section, the conclusions are presented.

\section{Literature Review}

De Swardt (2008) refers to online shopping as "any form of shopping that takes place via the Internet where electronic means are used to make purchases at virtual stores". Chiu et al. (2009) described that online shopping can be viewed as an exchange of time, effort and money for buying and receiving products and services while Zhang (2009) describes e-commerce as sweeping over all trading procedures such as online marketing, placing orders, payment and delivery system and also giving assistance to the marketing lifecycle. In this era of globalisation, the Internet plays an important role in human history and is soaring in popularity in almost every facet of the world. From networking to sharing information, the Internet has gone beyond that to become also a business tool, focusing on the delivering and trading of information, goods and services (Delafrooz et al., 2009). The Internet has been characterised as a global marketing channel where transactions can take place. The growth of Internet usage has been of an unprecedented magnitude and has fostered changes in lifestyles and behaviour of customer purchasing process. Ebay and Amazon are among the most widely recognised websites offering online shopping facilities (Park and Jun, 2003; Guo et al., 2011). A Nielsen Global Online Survey on online shopping habits in 2010 revealed that 824 million people across the globe have purchased online, mostly involved in the purchase of books followed by fashion related products, booking of air tickets and electronic equipment (D'Alessandro et al., 2012).

Along with the development of more shopping websites, the proliferation of online shopping has reshaped consumers' shopping behaviour across the world and its scope can therefore be extended to replace traditional methods of shopping (Cao, 2010). However, this e-market environment poses new challenges for businesses, inciting them to revise their marketing strategies to win and secure more targeted customers. Moreover, with online shopping, economic exchanges are not restricted by time investment, geographical locations or spatial barriers (Eastlick and Lotz, 2011). In the next section, we describe the methods used to identify the factors influencing online shopping in Mauritius.

\section{Methodology and Results}

In this section, we use the Principal Component Analysis (PCA) to obtain the relevant set of variables based on a sample of 224 respondents Table 1-8. We have circulated a questionnaire consisting of the following variables.

Table 1. List of variables

\begin{tabular}{ll}
\hline Variables & Labels \\
V1 & Can shop any time \\
V3 & Can save the effort of visiting stores \\
V4 & Can save time \\
V5 & More variety in terms of choice \\
V6 & Products are of better quality \\
V7 & Products are available at lower prices \\
V8 & Can get good product information online \\
V9 & Access to feedbacks from previous buyers \\
V10 & To try a new experience for fun \\
V11 & Web design/ features are attractive \\
V12 & Lack of trust in online companies/ websites \\
V13 & May not receive product ordered \\
V14 & Credit card number may not be secure \\
V15 & Inability to touch and examine products \\
V16 & May receive incorrect product instead of the one ordered \\
V17 & Quality of products may not match description on the Internet \\
V18 & No interpersonal interaction between buyer and seller \\
V19 & Too complicated to place an order \\
V20 & Pictures take too long to come up on screen \\
\hline
\end{tabular}


Table 2. KMO and bartlett's test

Kaiser-meyer-olkin measure of sampling adequacy

Bartlett's test of sphericity

$\begin{array}{lr}\text { Approx. Chi-square } & 2749.789 \\ \text { Df } & 190.000 \\ \text { Sig. } & 0.000\end{array}$

Table 3. Communalities table

Communalities

\begin{tabular}{lll} 
& Initial & Extraction \\
\hline V1 & 1.000 & 0.787 \\
V2 & 1.000 & 0.798 \\
V3 & 1.000 & 0.773 \\
V4 & 1.000 & 0.703 \\
V5 & 1.000 & 0.711 \\
V6 & 1.000 & 0.422 \\
V7 & 1.000 & 0.674 \\
V8 & 1.000 & 0.602 \\
V9 & 1.000 & 0.613 \\
V10 & 1.000 & 0.712 \\
V11 & 1.000 & 0.600 \\
V12 & 1.000 & 0.724 \\
V13 & 1.000 & 0.632 \\
V14 & 1.000 & 0.624 \\
V15 & 1.000 & 0.681 \\
V16 & 1.000 & 0.754 \\
V17 & 1.000 & 0.611 \\
V18 & 1.000 & 0.692 \\
V19 & 1.000 & 0.712 \\
V20 & 1.000 & 0.510 \\
\hline
\end{tabular}

Extraction method: Principal component analysis

In order to perform the analysis, the scale was inverted for variables V11 to V20. A simple correlation analysis reveals that several pairs of variables are highly correlated. For instance, correlation between V1 and V2 is 0.788 and this implies that $\mathrm{V} 1$ is very likely to share the same factor as V2. However, if correlations between variables were small, factor analysis would not have been appropriate. As a preliminary step to a PCA, it was verified that the data adheres well to the suppositions of the model. The Mayer-Kaiser-Olkin (KMO) measure of sampling adequacy gives a value of $0.872(>0.5)$, which suggests that correlations between pairs of variables can be explained by other variables and therefore, factor analysis is appropriate for the data set. Also, the null hypothesis that the correlation matrix is an identity matrix is rejected, as shown by the small p-value of the Bartlett's Test of Sphericity.

The table of communalities shows the amount of common variation shared with the remaining variables after the desired numbers of factors have been extracted. For example, variable V2 has 0.799 in the communalities table below and this implies that $79.9 \%$ of that variable can be obtained from the other variables. However, the remaining $20.1 \%$ of that variable is unique to itself.

Based on this table, the variables account for at least $50 \%$ of variation in each of the variable, which is a highly satisfactory result. In the PCA, the proposed model only retains factors with an Eigen value $>1$ and eliminates other factors with Eigen value less than one. Hence, the table of Total Variance Explained below shows that a 4 factor model was extracted, accounting for $66.677 \%$ of the total variation in the data. From the table below, it can be observed that the first extracted factor accounts for a large part of the total variance explained in the data, followed by the other factors which account for lesser and lesser of the total variance.

The unrotated correlation yielded that all variables had high loadings on the first factor and thus the Varimax rotation had to be applied as a factor rotation technique for ease of interpretation.

The 4 factors can be categorized as:

Factor 1: Convenience, Product Selection and Information Search regrouping V1 to V8 variables

Factor 2: Security and Product Risk regrouping V11 to V16 variables

Factor 3: Lack of Physical Presence and Waiting time regrouping V17 to V20 variables

Factor 4: Enjoyment and Pleasure consisting V9 and V10 variables

The concluding note after performing factor analysis is that individuals based their perception towards online shopping on these four dimensions.

Moreover, the explanatory variables which might determine behaviour are: Gender, Age, Occupational group, Level of education, Head of household, Marital status, Family size, Internet access at home, Skills with respect to using the Internet and Frequency of going shopping in malls/shops.

A series of logistic regressions were fitted to the data in $\mathrm{R}$ and the G-statistics are listed below.

From the table above, it was found that seven predictors had statistically significant reduction in deviance, namely Age, Occupational group, Level of education, Marital status, Internet access at home, Rating of skills and Frequency of shopping in malls. The Pearson chi-square and Spearman correlation coefficient were used to look for any association between predictors, given some variables were nominal while others involved ranking. Variables having significant $p$-value $(p<0.05)$ were rejected since small $p$-values provide enough evidence against the null hypothesis that there is no association between the pair of variables. Initially, Occupational group was dropped while performing chisquare association since it was highly associated with other nominal variables like Marital status and Internet at 
home. On the other hand, an inspection of the correlation matrix suggested that Rating of skills had to be dropped since it was highly correlated with Age, Education and Frequency of shopping. Furthermore, Education was eliminated and association between the remaining variables and the other variables were tested using Pearson chi-square. Correlation between pairs of variables like Age and Internet at home and Internet at home and Marital status were found to be insignificant ( $>0.05$ ) but however Age had to be dropped since it was correlated with Marital status. Thus, Marital status and
Internet access at home and Frequency of shopping in malls/shops were found to be suitable for the model. Hence, the model proposed is Online Shopping Behaviour $=\mathrm{f}$ (Marital status, Internet at home, Frequency of shopping in malls/shops), as illustrated below:

$$
\log i t\left(\frac{\pi_{i}}{1-\pi_{i}}\right)=\text { cons } \tan t+\beta_{1} X_{1}+\beta_{2} X_{2}+\beta_{3} X_{3}
$$

where, $\pi_{i}$ is the probability of a person shopping online.

Table 4. Extraction method: Principal component analysis

\begin{tabular}{|c|c|c|c|c|c|c|c|c|c|}
\hline \multirow[b]{2}{*}{ Component } & \multicolumn{3}{|c|}{ Initial Eigenvalues } & \multicolumn{3}{|c|}{ Extraction sums of squared loadings } & \multicolumn{3}{|c|}{ Rotation sums of squared loadings } \\
\hline & Total & $\%$ of Variance & Cumulative \% & Total & $\%$ of Variance & Cumulative \% & Total & $\%$ of Variance & Cumulative $\%$ \\
\hline 1 & 7.29 & 36.423 & 36.423 & 7.29 & 36.423 & 36.423 & 4.66 & 23.284 & 23.284 \\
\hline 2 & 3.61 & 18.047 & 54.471 & 3.61 & 18.047 & 54.471 & 4.16 & 20.798 & 44.081 \\
\hline 3 & 1.42 & 7.103 & 61.574 & 1.42 & 7.103 & 61.574 & 2.41 & 12.07 & 56.151 \\
\hline 4 & 1.02 & 5.103 & 66.677 & 1.02 & 5.103 & 66.677 & 2.11 & 10.526 & 66.677 \\
\hline 5 & 0.85 & 4.271 & 70.948 & & & & & & \\
\hline 6 & 0.75 & 3.767 & 74.715 & & & & & & \\
\hline 7 & 0.65 & 3.271 & 77.986 & & & & & & \\
\hline 8 & 0.63 & 3.167 & 81.152 & & & & & & \\
\hline 9 & 0.58 & 2.916 & 84.068 & & & & & & \\
\hline 10 & 0.49 & 2.458 & 86.526 & & & & & & \\
\hline 11 & 0.44 & 2.200 & 88.726 & & & & & & \\
\hline 12 & 0.40 & 2.019 & 90.745 & & & & & & \\
\hline 13 & 0.34 & 1.701 & 92.447 & & & & & & \\
\hline 14 & 0.30 & 1.503 & 93.950 & & & & & & \\
\hline 15 & 0.26 & 1.307 & 95.257 & & & & & & \\
\hline 16 & 0.25 & 1.241 & 96.498 & & & & & & \\
\hline 17 & 0.22 & 1.080 & 97.578 & & & & & & \\
\hline 18 & 0.19 & 0.923 & 98.502 & & & & & & \\
\hline 19 & 0.15 & 0.770 & 99.272 & & & & & & \\
\hline 20 & 0.15 & 0.728 & 100.000 & & & & & & \\
\hline
\end{tabular}

Table 5. Extraction method: Principal component analysis. Rotation method: Varimax with Kaiser normalization

\begin{tabular}{|c|c|c|c|c|}
\hline & \multicolumn{4}{|c|}{ Component } \\
\hline & 1 & 2 & 3 & 4 \\
\hline $\mathrm{V} 1$ & 0.878 & & & \\
\hline $\mathrm{V} 2$ & 0.885 & & & \\
\hline V3 & 0.867 & & & \\
\hline V4 & 0.728 & & & \\
\hline V5 & 0.723 & & & \\
\hline V6 & 0.539 & & & \\
\hline V7 & 0.583 & & & \\
\hline V8 & 0.571 & & & \\
\hline V9 & & & & 0.696 \\
\hline V10 & & & & 0.817 \\
\hline V11 & & 0.705 & & \\
\hline V12 & & 0.831 & & \\
\hline V13 & & 0.718 & & \\
\hline V14 & & 0.723 & & \\
\hline V15 & & 0.803 & & \\
\hline V16 & & 0.862 & & \\
\hline V17 & & & 0.612 & \\
\hline V18 & & & 0.737 & \\
\hline V19 & & & 0.800 & \\
\hline V20 & & & 0.561 & \\
\hline
\end{tabular}


Table 6. Explanatory variables and reduction in deviance

\begin{tabular}{lrc}
\hline Explanatory variables & G-statistic & p-value \\
\hline Gender & 1.391 & 0.289 \\
Age & 15.903 & 0.003 \\
Occupational group & 24.611 & 0.000 \\
Level of education & 14.226 & 0.002 \\
Head of household & 2.775 & 0.096 \\
Marital status & 13.459 & 0.004 \\
Family size & 0.165 & 0.684 \\
Internet access at home & 15.270 & 0.000 \\
Rating of skills & 39.935 & 0.000 \\
Frequency of shopping in malls & 21.307 & 0.001 \\
\hline
\end{tabular}

Table 7. Degree of fit

\begin{tabular}{lllcc}
\hline Model & Deviance & d.f & Chi-square & Degree of fit \\
\hline $\begin{array}{l}\text { Null model } \\
\text { One Factor }\end{array}$ & 28.616 & 7 & 14.067 & Lack of fit \\
$\begin{array}{l}\text { Marital status } \\
\text { Internet at home }\end{array}$ & 13.459 & 3 & 7.815 & Lack of fit \\
$\begin{array}{l}\text { Two factors } \\
\text { M + I }\end{array}$ & 15.270 & 1 & 3.841 & Lack of fit \\
$\begin{array}{l}\text { Saturated Model } \\
\text { M I + MI }\end{array}$ & 2.3812 & 3 & 7.814 & Adequate fit \\
\hline
\end{tabular}

Table 8. Probability table for best model

\begin{tabular}{|c|c|c|c|c|c|}
\hline Internet access at home & Marital status & $\pi_{\mathrm{ij}}$ & Logit & Odds & Probability \\
\hline \multirow[t]{4}{*}{ Yes } & Single & $\pi_{11}$ & 0.1946 & 1.2148 & 0.5485 \\
\hline & Married with children & $\pi_{21}$ & -0.6604 & 0.5166 & 0.3406 \\
\hline & Married without children & $\pi_{31}$ & 0.1877 & 1.2065 & 0.5468 \\
\hline & Widowed/Divorced/Separated & $\pi_{41}$ & -19.8454 & 0.0000 & 0.0000 \\
\hline \multirow[t]{4}{*}{ No } & Single & $\pi_{12}$ & -1.5204 & 0.2186 & 0.1794 \\
\hline & Married with children & $\pi_{22}$ & -2.3754 & 0.0930 & 0.0851 \\
\hline & Married without children & $\pi_{32}$ & -1.5272 & 0.2171 & 0.1784 \\
\hline & Widowed/Divorced/Separated & $\pi_{42}$ & -21.9204 & 0.0000 & 0.0000 \\
\hline
\end{tabular}

The null hypothesis was therefore rejected if deviance was greater than the chi- square at $5 \%$ significance level. Starting with the null model, it can be concluded that there is enough evidence to reject the null hypothesis since the value for the deviance is greater than the critical value for $\chi^{2}$ at 7 degrees of freedom (i.e., $28.616>14.067)$ at $5 \%$ level of significance. Thus, a lack of fit in the null model indicates that a better model should be looked for.

After introducing Marital status in the model, the deviance reduces to 13.459 on 3 degrees of freedom. Since the value for the deviance is bigger than the critical value, Ho is rejected and it can be concluded that there is lack of fit in this model as well. After introducing Internet access at home in the model, the deviance reduces to 15.27 on 1 degree of freedom. Since the value for the deviance is bigger than the critical value, Ho is rejected and it can be concluded that there is lack of fit in this model and proceed to check for the next model. Introducing both Marital and Internet access at home in the model reduces the deviance to 7.814 on 3 degrees of freedom. Since, deviance is smaller than the critical value for $\chi^{2}$ at 3 degrees of freedom and $5 \%$ level of significance (i.e., $2.381<7.814$ ), there is not enough evidence to reject the null hypothesis that there is no lack of fit. Thus, since Marital status and Internet access at home added together improve the fit of the model, this was chosen as the best model and is presented as follows:

$$
\log i t\left(\pi_{i}\right)=\eta+\alpha_{i}+\beta_{j}
$$

where, $\eta=\operatorname{logit}$ for the reference category for both Marital status and Internet access at home

\section{Conclusion}

PCA results showed that 20 variables have been summarised into four factors which are namely 'convenience, product selection and Information search', 'Security and product risk', 'Lack of physical presence and waiting time' and lastly 'Enjoyment and pleasure'. Therefore attitudes towards online shopping are mostly 
influenced by these four factors in Mauritius. Furthermore, a Binary Logistic regression revealed that Marital status and Internet access at home are important predictors of online shopping behaviour. The model explains that online shopping behaviour, that is to shop online or not to shop, in terms of Marital status and if an individual has internet access at home or not, in an additive model. Results showed that respondents who were single and having internet access at home were found to have higher probability of shopping online.

\section{Funding Information}

The authors have no support or funding to report.

\section{Author's Contributions}

All authors equally contributed in this work.

\section{Ethics}

This article is original and contains unpublished material. The corresponding author confirms that all of the other authors have read and approved the manuscript and no ethical issues involved.

\section{References}

Cao, X., 2010. E-shopping, spatial attributes and personal travel: A review of empirical studies. Transportation Research Board.

Chiu, C., C. Chang, H. Cheng and Y. Fang, 2009. Determinants of customer repurchase intention in online shopping. Online Inform. Rev., 33: 761-784. DOI: $10.1108 / 14684520910985710$
D'alessandro, S., A. Girardi and L. Tiangsoongnern, 2012. Perceived risk and trust as antecedents of online purchasing behavior in the USA gemstone industry. Asia Pacific J. Market. Logist., 24: 433460. DOI: $10.1108 / 13555851211237902$

De Swardt, M., 2008. Factors influencing the choice to shop online: A psychological study in a South African context. PhD. Thesis, University of Pretoria.

Delafrooz, N., L.H. Paim, S.A. Haron, S.M. Sidin and A. Khatibi, 2009. Factors affecting students' attitude toward online shopping. Malaysia. Afr. J. Bus. Manage. 3: 200-209.

Eastlick, M.A. and S. Lotz, 2011. Cognitive and institutional predictors of initial trust toward an online retailer. Int. J. Retail Distribut. Manage., 39: 234-255. DOI: 10.1108/09590551111117527

Guo, S., M. Wang and J. Leskovec, 2011. The role of social networks in online shopping: Information passing, price of trust and consumer choice. Proceedings of the 12th ACM Conference on Electronic Commerce, Jun. 05-09, ACM New York, pp: 157-166. DOI: 10.1145/1993574.1993598

Kim, E. and Y. Kim, 2004. Predicting online purchase intentions for clothing products. Eur. J. Market., 38: 883-897. DOI: 10.1108/03090560410539302

Park, C. and J. Jun, 2003. A cross-cultural comparison of Internet buying behavior: Effects of Internet usage, perceived risks and innovativeness. Int. Market. Rev., 20: 534-553. DOI: 10.1108/02651330310498771

Zhang, L., 2009. Business model analysis for online social shopping companies. Case study: RunToShop Oy. MSc Thesis, Aalto University Library. 